\title{
Proceeding
}

11th World Congress of Performance Analysis of Sport, 16-18 November 2016. International Society of Performance Analysis of Sport. Alicante, Spain

\section{The performance success within the competitive equestrian field: A novice and intermediate rider focused investigation}

\author{
DANIEL ALEXANDER PETHO \\ University of Central Lancashire, United Kingdom
}

\begin{abstract}
The aim of the current study was to investigate Equestrian Sports Dynamics (Motivation, Coach-Athlete Relationship, Self-Efficacy and Training- both Physical and Mental) of affiliated U.K equestrian riders upon their performance success of affiliated competition across three disciplines, Showjumping, Dressage and Eventing (The three dominant disciplines in the Equine U.K.) A hybrid questionnaire was produced from the Coach-Athlete Relationship Questionnaire, Mental Toughness Inventory, Sports Motivational Scale-28, the Self-Efficacy Scale and one's own adopted and refined questions (for the physical training research). The total participants accepted ( $n=236$, Showjumping=107, British Eventing=49, British Dressage $=80$ ) and the total participants rejected $(n=144)$ were accounted. A multiple regression analysis was implemented with revealing findings. Motivation was significantly and negatively correlated with performance success on Novice Eventers and Intermediate Showjumpers. These proved to be the only predictors of performance success, however interestingly, it was found that the predictor variables across the disciplines and levels were for the most part, moderately and positively correlated upon each other. However, these findings were not significant. This suggests there is evidence for the Equestrian Sports Dynamics that do work in unison for future investigations on the relationship of these moderately correlated variables, despite nonsignificance. It is recommended that further investigations of these Equestrian Sports Dynamics are to be implemented to extend the understanding of this sporting phenomenon in utilising these key elements to push forward Britain's Equestrian rider performance which is to be replicated on the national and world stage. Key words: NONE-ELITE, SPORTS PEFORMANCE, EQUESTRIAN RIDERS, EQUESTRIAN SPORTS DYNAMICS.
\end{abstract}

\section{Cite this article as:}

Petho, D.A. (2017). The performance success within the competitive equestrian field: A novice and intermediate rider focused investigation. Journal of Human Sport and Exercise, 12(3proc), S857-S871. doi:https://doi.org/10.14198/jhse.2017.12.Proc3.10

Corresponding author. School of Psychology, University of Central Lancashire, United Kingdom.

E-mail: dpetho@uclan.ac.uk

11th World Congress of Performance Analysis of Sport, 16-18 November 2016. International Society of Performance Analysis of Sport. Alicante, Spain.

JOURNAL OF HUMAN SPORT \& EXERCISE ISSN 1988-5202

(c) Faculty of Education. University of Alicante

doi:10.14198/jhse.2017.12.Proc3.10 


\section{INTRODUCTION}

Mastery of modern day equestrianism has concurrently developed over the ages, recognising the potential of the equine counterpart. Amongst other sports, athletes, psychologists and coaches all have recognised the importance of psychological and physiological aspects to sporting performance success. Equestrian riders are most notably being left behind as the last bastion of underdeveloped sporting literature. Research such as motivation (Huitt, 2011; Weiner, 1974; Ryan \& Deci, 2000), the coach-athlete relationship (Jowet \& Poczwardowski, 2007) physical training and mental robustness (Wolframm, Shearman \& Micklewright. 2010; Von Borstel, 2007) and self-efficacy (Bandura, 1977, 1982, 1997; Feltz, Short, Sullivan \& Short. 2007) have proven dominant.

Current literature within sport performance has effectively focused on Self Efficacy (S-E) as the contender for predicting higher sporting performance (Devenport, 1997). S-E is defined as one's beliefs about their own capability to produce designated levels of performance that influence over events affecting their lives (Bandura, 1997). Perceived S-E demonstrates clear influence on motivation, the ability to endure strain and the degree to which one engages in numerous activities. This reflects a ones' own belief that one indeed can perform new and potentially difficult operations, to cope with adversity in various areas, and have the competence to deal with challenging experiences (Schwarzer, 1992). The current application of S-E is across a wide range of mainstream sports (Heazlewood \& Burke, 2011;Vargas-Tonsing, 2009; Nicholls, Polman, Levy \& Borkoles, 2010; Bandura, 2006; Sindon, 1999; Bouffard-Bouchard, 1990) and also more recently within Equestrianism (Whinton \& Beauchamp, 2014; Træen et al, 2015; O' Callaghan, 2015; Wolframm \& Micklewright, 2009; Meyers, Bourgeois, LeUnes \& Murray,1999). This injection of S-E into sport suggests allowance to greatly improve and develop one's performance within the sporting context.

Within equestrian sports, S-E proves unique as comparatively, performance does not depend solely upon human skill and ability but also upon that of the horse, and most crucially, the quality of integration between horse and rider (McGreevy, 2002; McGreevy, 2007). Whilst human social interaction focuses upon verbal communications, there is a greater dependence among horses on nonverbal communication expressed through body language due of the danger associated with vocal communication of attracting predators (Van Dierendonck \& Goodwin, 2005). Such awareness on the part of the horse implies that any minute changes of body position, muscular tension, respiration or even heart rate from the rider will be picked up and reacted upon by the horse (Wolframm \& Micklewright 2009). S-E would therefore play a crucial role within the disciplines of Dressage, Showjumping and Eventing as heightened levels of S-E will negatively correlate with levels of anxiety. Riders with low levels of confidence are more likely to feel that they are unable to control their horse, further increasing heightened debilitative cognitive anxiety (Whinton \& Beauchamp, 2014).

The historical anecdotal teachings of "remaining calm in the saddle, breathing, and quietness in the rider's hands and body" (Wilcox,1973) are supported by findings of somatic anxiety. Somatic anxiety is the physical component of anxiety demonstrating the physiological responses such as muscular tension (Endler, 1991). Therefore, it is speculated that horses have sensitive dependability to nonverbal communication and the horse will be sensitive to the riders' heightened somatic anxiety (Wolframm \& Micklewright, 2009). This will produce adverse effects on the entity and performance will reverse. Successful riders in higher classes and are open to new experiences (willing to learn/ motivation) produce higher S-E than other riders who do not (Træen et al, 2015; Meyers et al 1999).

The Transactional Model of Stress examines the delegation of perceptive views in order to cope within specific situations. Any conditions that potentially raise perceptions of threats or decrease coping appraisals 
may lead to a detrimental increase in anxiety and a decrease in performance (Lazarus and Folkman,1984). Thus suggesting a reduction in cognitive anxiety such as negative self-talk and increased self-confidence allows the elite rider perform without impairment (Wolframm \& Micklewright, 2009). Therefore, S-E is an important factor of performance success, however, motivation is noted to be similarly associated with this feature to further increase success.

Motivation is defined as the internal state or condition that activates behaviour and gives direction, providing desire or want that energizes and directs goal (Kleinginna \& Kleinginna, 1981). Within the sporting context, the more motivated one is, the sooner one will sportingly succeed and become better, all without apparent effort (Dragos, 2014. It is argued that individuals gain peak performance from the inverted "U" model whereby motivation is peaked concurrently with performance until it plateaus (Yerkes \& Dodson, 1908) thus, suggesting explanations of adverse performance. Theory's examining motivation have attempted to elaborate its application. Classical Conditioning states that the biological responses are associated stimuli and direct one's behaviour and Operant focusing on consequences. Applications of "punishment" provide incentives of negative behaviour which enables adverse performance (Huitt \& Hummel, 1997a; Huitt \& Hummel, 1997b). This would explain why specific individual's performance would stagnate with immediate effects.

Attribution Theory (Hieder, 1958; Weiner, 1974) explains performance by offering specific attributions consisting of intrinsic and extrinsic motivations. Theoretically, for one to be in control and intrinsically motivated will produce positive sporting performance. Riders demonstrating low levels of confidence are more likely to be lacking in control of their horse, further increasing cognitive anxiety (Wolframm \& Micklewright 2009). This suggests to why performance does stagnate in equestrians as motivation and S-E bilaterally interrelate, however specific equestrian literature is lacking. Motivation within the equestrian world has remained largely anecdotal, however research investigating in other sports demonstrates the effectiveness with some applications within equestrianism (Sindon,1999). Motivation is recorded to be affected by the relationship between the coach-athlete relationship increases performance success (Smith et al 1995).

The Coach-Athlete Relationship (C-A R) is defined as the unique interpersonal relationship in which thoughts, emotions and behaviours of the athlete and the coach are mutually connected (Adie \& Jowett, 2010) It argued that the C-A R is at the heart of the competitive endeavour, whereby success is accountable for the quality of relationship between athlete and coach (Isoard-Gautheur et al, 2016). Athletes who played for trained coaches vs untrained coaches reported low anxiety levels, increased levels of self-esteem, motivational climates and liability towards their coach. (Smith, et al, 2007; Barnett, et al, 1992). It has not been completely differentiated between effective and ineffective behaviours of the coach (Claxton, 1988). This lends to speculation of coach behaviourisms upon athletes, it also found that the athletes' interpretation of the coach may be portrayed differently (Smith et al, 2007). Thus suggesting that the relationship between the coach and athlete must be that of a healthy, positive and unified for increased performance success. However, with the use of C-A R within other respectful sports proving successful, it is this factor of the C-A R that is required to be adopted within equestrianism. One must not perceive the underpinning factors unilaterally however, successful individuals requires parameters of fitness (Schoeman, et al, 2014).

Within equestrian sports, not only the horse but one must also be fit to equal the physical strain involved. One must be in both a fit mental and physical state before one can hope to produce their best form (Wilcox, 1973). Literature addressing this within riding community found amateur riders are significantly weaker than amateur sportspeople of other spotting disciplines (Halliday, Wilmot \& Randle, 2011). This suggests those in 
comparatively non-demanding roles (Showjumping and Dressage) to Eventing may require a status of "riding" fit, the notion to be fit for purposes specific to riding than another sport or overall (Halliday, Wilmot \& Randle, 2011). Further investigations found one -third of riders are too heavy (obese) for their horses, this calculation is means the rider is heavier than $15 \%$ horses own bodyweight (Halliday \& Randle, 2013). One would expect that Eventing would produce the highest fitness scores due to the discipline involving high physical demand, followed by Showjumping and Dressage respectively. However, this claim remains anecdotal due to a lack of literature within equestrianism.

Mental training in Dressage riders significantly increase the overall effect of the athlete, which regulated S-E (Wolframm \& Micklewright. 2009). This suggests that the use of mental training increases resilience in mental toughness, riders who had were better trained to control their anxiety are able to perform netter (Von Borstel, 2007). This suggests' mental training may indeed assist in improving emotional composure of the rider and produce harmonious horse- rider interactions. Indeed, across a range of sports, mental training has seen to produce increased performance of heightened success. (Hatzigeorgiadis, et al 2004; Hatzigeorgiadis et al, 2009).

The current study measured the effects of the predictor variables (Motivation, S-E, C-A R and Physical and Mental Training) on performance success. It was hypothesised the equestrian sports dynamics will have a positive significant impact upon sporting performance across the disciplines. Intermediates are expected to produce higher correlations between all predictor variables. Novice riders are expected to produce lower correlations and Eventing will produce higher rates of predictor variables on the criterion variable. Dressage expectations are heightened motivation. Showjumping expectations are higher of motivation and least physical fitness.

\section{METHODS AND METHODOLOGY}

\section{Design}

The current study implemented phenomenological methodology concurrently with archival methods. A between subjects quantitative design via self-report questionnaire (online and hard copy) was used to measure S-E, Motivation, Training of the rider (Physical and Mental) and C-A R. Alongside this, the participants archival performance history (of their disciplines governing body was used to compare against scores of the questionnaire. Participants were placed into one of two categories 1) Novice and 2) Intermediate. Categories identified as Novice; Showjumping (SJ) - British Novice, Discovery and Newcomers. British Eventing (BE) - BE80(T), BE90, BE 100 and BE100plus. British Dressage (BD) - Prelim, Novice and Elementary. Intermediates were identified as: SJ- Foxhunter, $1.30 \mathrm{~m}$ and $1.40 \mathrm{~m}$. BE- Novice, Intermediate and Advanced. BD - Medium, Advanced Medium and Advanced. Elite riders were not measured.

\section{Participants}

All participants were recruited via a volunteer sample online, and for hard copy selected venues of the United Kingdom. Participants were recruited online through the use of Social Media and businesses/governing bodies. All participants were required to be an active affiliated member of either one of the three Olympic equestrian disciplines (Dressage, Eventing or Showjumping). In order to allow more generalised validly, participants were recruited from all Regions of the UK to cancel out cultural regional variables. Participants were placed into one of two categories 1) Novice and 2) Intermediate. For identification of categories, see "Design" section. Elite riders were not measured. Total participants ( $n=380, S J=143, B E=53, B D=184$ ) was calculated. Participants rejected $(n=144)$. Accepted $(n=236, S J=107, B E=49, B D=80)$ were examined via an SPSS statistical software. F.E.I and para riders were accepted up to $2^{*}$ level and para riders were accepted 
on the grounds they were competing along able bodied competitors. Gender $(M=16, F=220)$ and age was also noted, the range age of participants $(n=236)$ was $18-78$ years. Age was not compared, grading of horse was not measured.

\section{Measures}

A hybrid questionnaire was made incorporating other questionnaires that had best fitted the equestrian application. Motivation sought the original Sports Motivational Scale (SMS- 28) (Pellietier et al, 1995). The questions presented gave a Likert Scale, this was replicated across the entirety of the questionnaire. A refined adaptation of Bandura (1977) produced S-E questions and measured in the same protocol. A revised version adapted from the Long Meta CART -Q (Jowett \& Ntoumanis, 2004) was implemented. Physical and Mental Training was measured from a combination of the MTQ (Clough et al, 2002). For both Novice and Advanced riders (Dressage), scores were based on the "old system" before the redistribution of the Bronze, Silver and Gold league system as of 1/1/2016.

\section{Procedure}

For the use of the database archives, respective governing bodies permission was sought (British Dressage, British Eventing and British Showjumping). Selected venues were also sought permission. The researcher ensured the participants understood the aims of the research and what was required of them. Once the participants signed the informed consent documentation the researcher conducted data collection. Hard Copy participants were required to complete a 32 question self- report questionnaire incorporating a 10 point Likert scale on equestrian sports dynamics. Before taking the questionnaire, participants were supplied with an information sheet and were reminded their ethical rights. For the online participants, they were reminded that they may withdraw by closing the page "tab". Participants were requested to provide their own and their competing horse(s) affiliated numbers on the consent sheet. Upon completion the participant submitted or returned the questionnaire. Prior to final submission, they were reminded that once they submitted or returned questionnaires, they were "locked in" and could not withdraw. The participant was given a debrief sheet informing them of the research motivation and what is expected of the outcome.

\section{RESULTS}

\section{Results}

Entire sample averages were calculated for all predictor variables, including all disciplines. See Table 1 below for the means and standard deviations. A copy of the raw data may be requested from the author.

Table 1. Means (and standard deviations) on the whole sample on the reports on Motivation, C-A Relationship, S-E, Physical and Mental Training.

\begin{tabular}{lccccc}
\hline Motivation & $\begin{array}{c}\text { Coach-Athlete } \\
\text { Relationship }\end{array}$ & Self-Efficacy & $\begin{array}{c}\text { Training } \\
\text { (Physical) }\end{array}$ & $\begin{array}{c}\text { Training } \\
\text { (Mental) }\end{array}$ \\
\hline Mean (SD) & $8.31(.25)$ & $7.73(1.71)$ & $6.82(1.11)$ & $8.81(2.93)$ & $7.65(1.56)$ \\
\hline
\end{tabular}

Upon compared to the maximum score of each predictor across the disciplines Motivation proved to be high, S-E, Coach- Athlete Relationship and Physical and Mental Training proved to be moderate.

A Pearson's correlation analysis was implemented across the study variables viewing potential patterns of correlations and evidence of collinearity. Table 2, 3, 4, 5, 6 \& 7 demonstrate bivariate correlations between predictors (Motivation, C-A R, S-E, Physical Training and Mental Training) and the criterion variable (Mean Performance Score) of all Novice and Intermediate scores. 
Table 2. Eventing Novice

1. Motivation

2. Self Efficacy

3. Coach-Athlete Relationship

4. Training (Physical)

5. Training (Mental)

6. Mean Performance Score

\begin{tabular}{|c|c|c|c|c|c|}
\hline 1 & 2 & 3 & 4 & 5 & 6 \\
\hline & \multirow{5}{*}{383} & $.620^{* \star}$ & $.481^{*}$ & .048 & $-.604^{* *}$ \\
\hline & & $.481^{*}$ & .128 & -.093 & $-.466^{*}$ \\
\hline & & & $611^{* *}$ & .130 & $-.497^{*}$ \\
\hline & & & & -.383 & -.014 \\
\hline & & & & & .253 \\
\hline
\end{tabular}

Pearson's correlation coefficients between predictor and criterion variables $*$ = significant at $0.01,{ }^{*}=$ significant at 0.05

Table 3. Eventing Intermediate

\begin{tabular}{lcccccc}
\hline & $\mathbf{1}$ & $\mathbf{2}$ & $\mathbf{3}$ & $\mathbf{4}$ & $\mathbf{5}$ & $\mathbf{6}$ \\
\hline 1. Motivation & & .125 & .213 & .340 & .170 & .012 \\
2. Self Efficacy & & & $.540^{*}$ & .097 & .284 & -.064 \\
3. Coach-Athlete Relationship & & & & $.474^{*}$ & .274 & -.145 \\
4. Training (Physical) & & & & & .399 & .019 \\
5. Training (Mental) & & & & & & .146 \\
6. Mean Performance Score & & & & & & \\
\hline
\end{tabular}

Pearson's correlation coefficients between predictor and criterion variables

$\cdots=$ significant at $0.01,{ }^{*}=$ significant at 0.05

Table 4. Showjumping Novice

\begin{tabular}{lcccccc}
\hline & $\mathbf{1}$ & $\mathbf{2}$ & $\mathbf{3}$ & $\mathbf{4}$ & $\mathbf{5}$ & $\mathbf{6}$ \\
\hline 1. Motivation & & $.308^{* *}$ & .210 & $.522^{* *}$ & .127 & .082 \\
2. Self Efficacy & & & $.459^{* *}$ & $.546^{* *}$ & $.354^{*}$ & -.123 \\
3. Coach-Athlete Relationship & & & & .198 & .162 & -.095 \\
4. Training (Physical) & & & & & $.427^{* *}$ & -.072 \\
5. Training (Mental) & & & & & & -.038 \\
6. Mean Performance Score & & & & & &
\end{tabular}

Pearson's correlation coefficients between predictor and criterion variables $\cdots=$ significant at $0.01, *=$ significant at 0.05

Table 5. Showjumping Intermediate

\begin{tabular}{|c|c|c|c|c|c|c|}
\hline & 1 & 2 & 3 & 4 & 5 & 6 \\
\hline 1. Motivation & & .060 & $.434^{\star \star}$ & $.559^{\star \star}$ & .127 & $-.472^{* *}$ \\
\hline 2. Self Efficacy & & & .249 & .150 & .068 & -.014 \\
\hline 3. Coach-Athlete Relationship & & & & $.445^{\star \star}$ & .074 & -.092 \\
\hline 4. Training (Physical) & & & & & -.110 & $-.355^{*}$ \\
\hline $\begin{array}{l}\text { 5. Training (Mental) } \\
\text { 6. Mean Performance Score }\end{array}$ & & & & & & -.178 \\
\hline
\end{tabular}


Pearson's correlation coefficients between predictor and criterion variables

$\cdots=$ significant at $0.01, *=$ significant at 0.05

Table 6. Dressage Novice

\begin{tabular}{lllllll}
\hline & $\mathbf{1}$ & $\mathbf{2}$ & $\mathbf{3}$ & $\mathbf{4}$ & $\mathbf{5}$ & $\mathbf{6}$ \\
\hline 1. Motivation & & $.657^{* *}$ & .239 & $.600^{* *}$ & .126 & .169 \\
2. Self Efficacy & & & $.358^{* *}$ & $.528^{* *}$ & .222 & .023 \\
3. Coach-Athlete Relationship & & & & $.464^{* \star}$ & .003 & -.140 \\
4. Training (Physical) & & & & & -.015 & -.052 \\
5. Training (Mental) & & & & & & .080 \\
6. Mean Performance Score & & & & & & \\
\hline
\end{tabular}

Pearson's correlation coefficients between predictor and criterion variables

$\cdots=$ significant at $0.01, *=$ significant at 0.05

Table 7. Dressage intermediate

\begin{tabular}{|c|c|c|c|c|c|c|}
\hline & 1 & 2 & 3 & 4 & 5 & 6 \\
\hline 1. Motivation & & $.581^{* *}$ & .281 & $.554^{*}$ & $.515^{\star *}$ & -.068 \\
\hline 2. Self Efficacy & & & $.500^{*}$ & .394 & $.514^{*}$ & -.014 \\
\hline 3. Coach-Athlete Relationship & & & & $.659^{\star \star}$ & .385 & $-.025^{\star}$ \\
\hline 4. Training (Physical) & & & & & .389 & -.092 \\
\hline 5. Training (Mental) & & & & & & -.078 \\
\hline 6. Mean Performance Score & & & & & & \\
\hline
\end{tabular}

Pearson's correlation coefficients between predictor and criterion variables

$\cdots=$ significant at $0.01,{ }^{*}=$ significant at 0.05

Collinearity measured at or surpassing .70 level. The prelim correlation demonstrated no evidence between predictor variables. However, there was scores found close to this level throughout both novice and intermediates of all disciplines. Six follow up multiple regressions were implemented. Table 8,9,10,11,12 and 13 show the relationship between five predictors and the criterion variable.

Table 8. Eventing Novice

\begin{tabular}{lll}
\hline Predictor & Beta & Significance \\
\hline Motivation & -.48 & .026 \\
Self-Efficacy & -.13 & .494 \\
Coach- Athlete Relationship & -.39 & .128 \\
Mental Training & .36 & .097 \\
Physical Training & .17 & .321 \\
\hline Adjusted R & .46 & \\
\hline ANOVA & $\mathrm{F}(5,23)=4.97, \mathrm{p}=.005$ & \\
\hline
\end{tabular}

Table 8 demonstrates a negative relationship between motivation and novice performance $(B=-.48, p=.026)$ suggesting that an increase in motivation produces the effect of lower performance. S-E, C-A R, physical and mental training showed no significance in predicting sports performance. The Adjusted $\mathrm{R}^{2}$ shows that $46 \%$ of variance in reports of performance is explained by the effect of reports of motivation, and this is a significant contribution to explaining the variance in performance $(F(5,23)=4.97, p=.005)$. Table 9 presents the second 
Eventing multiple regression which assessed Intermediate Event riders across the same predictor and criterion variable.

Table 9. Eventing Intermediate

\begin{tabular}{lll}
\hline Predictor & Beta & Significance \\
\hline Motivation & .009 & .972 \\
Self-Efficacy & .001 & .996 \\
Coach- Athlete Relationship & -.228 & .462 \\
Mental Training & .061 & .821 \\
Physical Training & .186 & .449 \\
\hline Adjusted R & .17 & \\
\hline ANOVA & $\mathrm{F}(5,25)=.262, \mathrm{p}=.928$ \\
\hline
\end{tabular}

Table 9 demonstrates no significant relationship between any predictors and the criterion variable. This suggests that Intermediate Eventers performance success is not dependable to the criterion variables. The Adjusted $\mathrm{R}^{2}$ shows that $17 \%$ of variance in reports of predictor variables explain the effect on performance with a non-significant contribution $(F(5,25)=.262, p=.928)$. Table 10 presents the first Showjumping multiple regression assessing novice showjumpers across the same process.

Table10. Showjumping Novice

\begin{tabular}{lll}
\hline Predictor & Beta & Significance \\
\hline Motivation & .18 & .22 \\
Self-Efficacy & -.10 & .56 \\
Coach- Athlete Relationship & -.07 & .61 \\
Mental Training & -.12 & .52 \\
Physical Training & .03 & .81 \\
\hline Adjusted R & .04 & \\
\hline ANOVA & $\mathrm{F}(5.75)=.546, \mathrm{p}=.741$ \\
\hline
\end{tabular}

Table 10 demonstrates no significant relationship between any predictors and the criterion variable. This suggests that novice showjumpers performance success is not dependable to the predictor variables. The Adjusted $\mathrm{R}^{2}$ shows that $4 \%$ of variance in reports of predictor variables explain the effect on performance and this is a non-significant contribution $(F(5,75)=.546, p=.741)$ Table 11 presents the second Showjumping multiple regression assessing Intermediate Showjumpers across the same process.

Table 11. Showjumping Intermediate

\begin{tabular}{lll}
\hline Predictor & Beta & Significance \\
\hline Motivation & -.44 & .04 \\
Self-Efficacy & .002 & .99 \\
Coach- Athlete Relationship & .18 & .33 \\
Mental Training & -.18 & .37 \\
Physical Training & -.12 & .47 \\
\hline Adjusted R & .15 & \\
\hline ANOVA & $\mathrm{F}(5,34)=4.19, \mathrm{p}=.083$ & \\
\hline
\end{tabular}


Table 11 demonstrates a negative significance between motivation and performance success $(B=-.44, p=.04)$ suggesting that the increase in motivation results in the stagnation of performance success. S-E. C-A R, physical and mental training were found not to be significant predictors of performance success. The adjusted $\mathrm{R}^{2}$ shows that $15 \%$ of variance in reports of performance success is explained by the effect of reports motivation, and this is significant to contributing an explanation of variance in performance success $(F(5,34)=4.19, p=.083)$. Table 12 presents the first Dressage multiple regression assessing Novice Dressage across the same process.

Table 12. Novice Dressage

\begin{tabular}{lll}
\hline Predictor & Beta & Significance \\
\hline Motivation & .342 & .087 \\
Self-Efficacy & -.091 & .634 \\
Coach- Athlete Relationship & -.118 & .451 \\
Mental Training & -.153 & .417 \\
Physical Training & .056 & .692 \\
\hline Adjusted R & .46 & \\
\hline ANOVA & $\mathrm{F}(5,56)=.94, \mathrm{p}=.462$ & \\
\hline
\end{tabular}

Table 12 demonstrates no significant relationship between any predictors and the criterion variable. This suggests that Novice Dressage performance success is not dependable due to the predictor variables. The Adjusted $\mathrm{R}^{2}$ shows that $46 \%$ of variance in reports of predictor variables explain the effect on performance and this is a non-significant contribution $(F(5,23)=.261, p=.928)$. Table 13 presents the second Dressage multiple regression which assessed Intermediate Dressage across the same process.

Table 13: Intermediate Dressage

\begin{tabular}{lll}
\hline Predictor & Beta & Significance \\
\hline Motivation & -.355 & .329 \\
Self-Efficacy & -.199 & .552 \\
Coach- Athlete Relationship & -.083 & .827 \\
Mental Training & .083 & .832 \\
Physical Training & .002 & .995 \\
\hline Adjusted R & .19 & \\
\hline ANOVA & $\mathrm{F}(5,23)=.261, \mathrm{p}=.928$ \\
\hline
\end{tabular}

Table 13 demonstrates no significant relationship between any predictors and the criterion variable. This suggests that Intermediate Dressage performance success is not dependable to the predictor variables. The Adjusted $\mathrm{R}^{2}$ shows that $19 \%$ of variance in reports of predictor variables explain the effect on performance and this is a non-significant contribution $(F(5,23)=.261, p=.928)$.

\section{DISCUSSION}

Motivation was proven to be the only significant predictor of performance success across two category levels. The first was Novice Eventing and secondly, Intermediate Showjumping. This does partly support the hypothesis that motivation alone cannot predict improved performance success and therefore other variables are required for performance to improve in equestrian riders. Within Novice Eventing and Intermediate Showjumping, motivation was negatively significant with performance success. This suggests that motivation increases and decreases with performance across variety of sporting levels. This may explain specifics within 
equestrian riders, for intermediate showjumpers the current status may be satisfactory in their performance success and therefore motivation decreases. However, when their performance decreases this will enact intermediate showjumpers to increase their motivation to then remain in the intermediate sphere. Another explanation is potentially that many novice eventers are sampling the sport. Once these riders have attained a comfortable competition level with their horse, this may reduce motivation as they feel they have reached their peak. Supporting the inverted $U$ hypothesis, demonstrating when ones' peak performance levels stabilises, motivation will fall (Yerkes \& Dodson, 1908).

The negative significant finding contradicts the original hypothesis when performance success decreases, so should all the predictor variables. Further findings from all other categories, none of the predictor variables were significant predictors of the criterion variable on performance success. This suggests that performance success is not due to the four variables measured, rather it be to other non-measured variables such as trustworthiness.

Within specific categories, there was a significant correlation between some of the predictor variables, suggesting these do have a concurrent effect to the performance success. In Novice Eventing, motivation demonstrates moderate, positive and significant correlations with C-A R and mental training and C-A R and physical training. Intermediate Eventing demonstrated a positive moderate correlation between S-E and C-A $\mathrm{R}$ and $\mathrm{C}-\mathrm{A} \mathrm{R}$ and physical training. Showjumping demonstrated a mixture of positive weak to moderate correlations between the two levels. Dressage demonstrated moderate to strong positive correlations between motivation and S-E across both levels and strong to moderate correlations between motivation, SE, C-A R and physical training. Between each discipline there are separate attitudes prioritising different aspects, which given the disciplines vary from each other would make logical sense.

According to this study, in the Novice and Intermediate field, C-A R, S-E and training all seem to have a nonsignificant impact upon one's performance success at these levels across the spectrum of disciplines. These results therefore, do not support the hypothesis that the equestrian sports dynamic will have a significant impact upon sporting performance. The current study aimed to take into account the equestrian sports dynamics to facilitate the explanation of sporting performance success in non-elite riders. As in other sporting areas (non-equine) all of these variables working multilaterally would predict the higher levels of success. Therefore, it would be beneficial to incorporate these variables into the equestrian sphere, as they are predicting the same human behaviour. Equestrianism is also a team sport, with the team focus being between the horse and rider.

The positivity levels of C-A R would prove useful for the sporting success as an athlete who understands their coach and vice versa prove to have increased likelihood of sporting success. The rider would want to please their coach by taking on board what they have learned and implementing it. Indeed, the use of motivation has been proven to contribute to sporting success in other spheres of sport (Dragos, 2014; Rottensteiner et al 2015). In regards to Training, it has been found that if one is to be physically fit, will be more mentally resilient (Deuster \& Silverman, 2013). They will therefore produce better reaction times, better analysis of the situation and a better sporting ability.

Non-significant findings may be theorised for many of the participants may have produced social desirability, whereby when presenting a higher social image of one's self (especially at the novice levels) would provide a false validation of which may explain why there is a higher non-significant result on performance success scores (Van De Mortal, 2008). The results support Bandura's work that S-E has an effect on motivation (Huitt, 2011). In Novice Dressage and Showjumping and Intermediate Dressage riders, S-E was positively 
correlated with motivation. This suggests the predictor variables do have some effect on predicting performance which was undiscovered in the study. This supports evidence demonstrating S-E a somewhat influence on motivation to which one provides evidence via the moderate correlations. (Bandura, 1986; Sindon, 1999; O' Callaghan, 2015).

The results of the current study presented no significant results on the effect of S-E. Surprisingly this was most notable in the Intermediate eventing where this would matter the most within the cross country phase whereby high S-E would be required. However, the current study was measured over the winter months November 2015 - March 2016. Therefore, a false sense of security and scrutiny to how one actually feels in contrast to the current perspective such as other disciplines which the season is all year round is prominent.

Wolframm \& Micklewright (2009) speculated that the physiological dependability response of the horse from the rider anxiety. As the motivation S-E correlation is established, this may explain why S-E and motivation have not been significant predictors of performance success. If motivation is low, this will have a knock on effect on S-E, to which give more of the notion to the horses' performance alone as opposed to the human aspect of the combination. This aspect would be plausible for the Showjumping, however one must investigate the use of Dressage to this theory. For Novice Dressage riders, this may produce an effect of motivation as $p=.087$ demonstrating that there some effect but not enough to produce a significant result. However, within Intermediate Dressage riders, this was proven to not be the case, in contrast to Dragos (2014) it was found that Motivation did not explain the performance success in the majority of riders.

From the literature, the current study has proven to be the catalyst breaking into a new frontier, measuring the equestrian sports dynamics as a whole rather than a unilateral aspect. It has been noted that there are those who indeed do not use a sports coach, and instead learn from what is read/seen. In addition, parents with their own experience can be viewed as coaches, although it is apparent that in this situation there may be conflicts between coach and athlete due to parent- child ego, relationship and perception (Dorsch, Smith \& Dotterer, 2016). Although anecdotal, this may provide explanation to why the results provided an insignificant finding. Comparatively, it is seen that elite riders who compete on an Olympic level will have dedicated coaches who demonstrate professionalism without the parental relationship to the rider.

The hypothesis theorised equestrian sports dynamics would work concurrently and co-operate to be the determining factor of performance success of the equestrian rider. As the groups works unilaterally performance success increases, when one predictor falters, then performance is adverse. The hypothesis was not confirmed as, there is evidence of some variables correlated and evidence of some predictor variables are significant in performance success. However, the predictor variables did not meet the study hypothesis. The study aimed to provide clarity within equestrian sporting success. This was to identify key areas where the sport may promote more sporting success for rider psychology. Despite the non-significant findings, the $p$ value did demonstrate a difference in how the predictor variables affected the criterion variable. In the Novice levels, the $p$ value demonstrated a closer value to .05 than Intermediates by a considerable way with some overlap between the two (except Intermediate Showjumping). Therefore, suggesting there is an interaction present between all predictor variables on the criterion variable, however this remains largely non-significant.

It was unexpected to attain a paradoxical, negative significance of motivation (Novice Eventing and Intermediate Showjumping). One would logically assume that motivation and performance would positively correlate across the spectrum of all levels and disciplines. This logic would be adopted to all predictor variables within the study. More surprisingly was the level of non-significance produced by all variables across 
the study, according to these levels of insignificance, there is more to be accountable towards performance success within the three disciplines. Social desirability may have been presented within the current study with the notion that participants may wish to perceptively better themselves rather than give a true statement which may detrimentally affect the results. As the study required the specific name or affiliated number of the horse and rider.

Retrospective data for the Eventing riders may have provided a distorted answer as the event season (March - October) was closed over the winter months. This limited the use of true "in the present" statements as the Dressage and Showjumpers did have. In order to correct this, one must measure the eventers within the height to late season of that calendar year to avoid retrospective views from the 4-6 months previous. However, this is possible a retrospective aspect for the Eventing demographic experiencing heightened S-E from the use of hunting over the winter months.

The quick questionnaire implemented didn't take up too much of the participant's time. While at the showground, this gave the participant time to reflect, remain stimulated and not distract them. This method did not intrude in any BPS guidelines and it is suitable for both offline and online participants as was user friendly. This allows for a solid basis, should a qualitative design be implemented, social-desirability is a potential risk. With the use of the current study, this aims to cancel out the use of social-desirability to give a true result. Therefore, the participant is more likely to produce true and realistic statement as their scores are compared to their performance on the governing body's database.

\section{CONCLUSIONS}

The current study found that, contrary to evidence, the equestrian sports dynamics had little significance on the performance success of equestrian riders across the three disciplines. However, Motivation in Novice Eventers and Intermediate showjumpers was negatively correlated but significant with performance success. Many predictor variables are significantly inter-correlated, strengthening the argument that these factors are controllers of performance success despite non-significance. As this is not significant on the criterion variable, it has placed a foundation in this literature for future research. Further revised research into this new branch of performance literature in equestrianism is advised to attain a further understanding of the Equestrian Sports Dynamics on performance success via qualitative methods. One must note that each discipline prioritises on specific predictor variables for performance success. Therefore, it's recommended to follow up this research into the specifics of each criterion variable of Equestrian Sports Dynamics.

\section{REFERENCES}

1. Adie, J.W. \& Jowett, S. (2010). Meta-Perceptions of the Coach-Athlete Relationship, Achievement Goals, and Intrinsic Motivation Among Sport Participants, Journal of Applied Social Psychology, 40(11), 2750-2773. https://doi.org/10.1111/j.1559-1816.2010.00679.x

2. Bandura, A. (1997). Self-Efficacy and Health Behaviour. In A. Baum, S. Newman, J. Wienman, R. West, \& C. McManus (Eds.), Cambridge Handbook of Psychology, Health and Medicine, 160-162. Cambridge: Cambridge University Press.

3. Bandura, A. (1977). Self-Efficacy: Toward A Unifying Theory of Behavioural Change', Psychological Review, 84(2), 191-215. https://doi.org/10.1037/0033-295X.84.2.191

4. Bandura, A. (1986). Social Foundations of Thought and Action: A Social Cognitive Theory. 7th ed. United States: Prentice-Hall. 
5. Bandura, A. (2006). Guide For Constructing Self-Efficacy Scales. In F. Pajares \& T. Urdan (Eds.). Self-efficacy Beliefs of Adolescents, 5, 307-337. Greenwich, CT: Information Age Publishing.

6. Bandura, A. (1982). The Assessment and Predictive Generality of Self-Percepts of Efficacy. Journal of Behavior Therapy and Experimental Psychiatry, 13, 195-199. https://doi.org/10.1016/00057916(82)90004-0

7. Barnett, N. P., Smoll, F. L. \& Smith, R. E. (1992). Effects of Enhancing Coach-Athlete Relationships on Youth Sport Attrition. The Sport Psychologist, 6, 111-127. https://doi.org/10.1123/tsp.6.2.111

8. Bouffard-Bouchard, T. (1990). Influence of Self-Efficacy on Performance in A Cognitive Task, The Journal of Social Psychology, 130(3), 353-363. https://doi.org/10.1080/00224545.1990.9924591

9. Claxton, D. B. (1988). A Systematic Observation of More and Less Successful High School Tennis Coaches. Journal of Teaching in Physical Education, 7, 302-310. https://doi.org/10.1123/itpe.7.4.302

10. Clough, P., Earle, K. \& Sewell, D. (2002). Mental Toughness: The Concept and Its Measurement. In I. Cockerill (Ed.), Solutions in Sport Psychology, 32-46. London: Thomson Learning.

11. Deuster, P. A., \& Silverman, M. N. (2013). Physical fitness: a pathway to health and resilience. US Army Medical Department Journal, 24-35.

12. Devenport, T. (1997). Perceptions of The Contribution Of Psychology To Success In Elite Kickboxing. Journal of Sports Sciences and Medicine, CSSI, 99-107.

13. Dorsch, T., Smith, A. \& Dotterer, A (2016). Individual, Relationship, And Context Factors Associated With Parent Support And Pressure In Organized Youth Sport, Psychology Of Sport \& Exercise, 23, 132-141. https://doi.org/10.1016/i.psychsport.2015.12.003

14. Dragos, P. F. (2014). Study regarding the role of motivation in the sport performance activities. Baltic Journal of Health \& Physical Activity, 6(1), 48-55. http://doi.org/10.2478/bjha-2014-0006

15. Endler, N.S., Edwards, J.M., \& Vitelli, R. (1991). Multidimensional Anxiety Scales (EMAS): Manual. Los Angeles, CA: Western Psychological Services.

16. Feltz, D., Short, S., Sullivan, P. \& Short, R.A. (2007). Self - Efficacy in Sport. Leeds: Human Kinetics Publishers.

17. Halliday, E., Willmott, B. \& Randle, H. (2011). Physiological Measures of Fitness of Riders and NonRiders, Journal of Veterinary Behavior: Clinical Applications and Research, 6(5), pp. 300-301. https://doi.org/10.1016/j.jveb.2011.05.029

18. Halliday, E. \& Randle, H. (2013). The Horse and Rider Bodyweight Relationship Within The UK Horse Riding Population, Journal of Veterinary Behavior: Clinical Applications and Research, 8(2), 8-9. https://doi.org/10.1016/j.jveb.2012.12.020

19. Hatzigeorgiadis, A.N. Theodorakis, N. Zourbanos. (2004). Self-Talk In The Swimming Pool: The Effects Of Self-Talk On Thought Content And Performance On Water-Polo Tasks. Journal Applied Sport Psychology, 16, 138-150. https://doi.org/10.1080/10413200490437886

20. Hatzigeorgiadis, A., Zourbanos, N., Mpournpaki, S., \& Theodorakis. Y. (2009). Mechanisms Underlying The Self-Talk-Performance Relationship: The Effects Of Motivational Self-Talk On SelfConfidence And Anxiety. Psychology Sport Exercise, 10, 186-192. https://doi.org/10.1016/i.psychsport.2008.07.009

21. Heazlewood, I. \& Burke, S. (2011). Self-Efficacy and Its Relationship To Selected Sport Psychological Constructs In The Prediction Of Performance In Ironman Triathlon, Journal of Human Sport and Exercise, 6(2), 328-350. https://doi.org/10.4100/jhse.2011.62.14

22. Heider, F. (1958). The Psychology of Interpersonal Relations. New York: Wiley. https://doi.org/10.1037/10628-000

23. Huitt, W., \& Hummel, J. (1997a). An Introduction to Classical (Respondent) Conditioning. Educational Psychology Interactive. Valdosta, GA: Valdosta State University. Retrieved from http://www.edpsycinteractive.org/topics/behavior/classcnd.html (Accessed: 1 March 2016). 
24. Huitt, W., \& Hummel, J. (1997b). An Introduction to Operant (Instrumental) Conditioning. Educational Psychology Interactive. Valdosta, GA: Valdosta State University. Retrieved from http://www.edpsycinteractive.org/topics/behavior/operant.html(Accessed:1March2016).

25. Huitt, W. (2011). Motivation to learn: An overview. Educational Psychology Interactive. Valdosta, GA: Valdosta State Universitywww.edpsycinteractive.org/topics/motivation/motivate.html (Accessed:2 March 2016).

26. Isoard-Gautheur, S., Trouilloud, D., Gustafsson, H. \& Guillet-Descas, E. (2016). Associations Between The Perceived Quality Of The Coach-Athlete Relationship And Athlete Burnout: An examination of the mediating role of achievement goals, Psychology of Sport and Exercise, 22, 210217. https://doi.org/10.1016/i.psychsport.2015.08.003

27. Jowett, S. \& Ntoumanis, N. (2004).The Coach-Athlete Relationship Questionnaire (CART-Q): Development and Initial Validation. Scandinavian Journal of Medicine \& Science In Sports, 14 (4). 245-257. https://doi.org/10.1111/j.1600-0838.2003.00338.x

28. Jowett, S., \& Poczwardowski, A. (2007). Understanding the Coach-Athlete Relationship.

29. Kleinginna, P., Jr., \& Kleinginna A. (1981). A Categorized List of Motivation Definitions, With Suggestions for A Consensual Definition. Motivation and Emotion, 5, 263-291. www.edpsycinteractive.org/topics/motivation/motivate.html (Accessed:2 March 2016). https://doi.org/10.1007/BF00993889

30. Lazarus, R.S. \& Folkman, S. (1984). Stress Appraisal and Coping. New York: Springer Publishing Company, 141-178.

31. McGreevy, P.D. (2002). Development and Resolution of Behavioural Problems in The Ridden Horse. Havemeyer Workshop on Horse Behaviour and Welfare, Holar, Iceland, 13, 110-115.

32. McGreevy,P.D. (2007). The Advent of Equitation Science. The Veterinary Journal 174 (3), 492-500. https://doi.org/10.1016/j.tvil.2006.09.008

33. Meyers, M.C., Bourgeois, A.E. LeUnes, A. \& Murray, N.G. (1999). Mood and Psychological Skills of Elite and Sub-Elite Equestrian Athletes. Journal of Sport Behaviour. 22(3), 399-409.

34. Nicholls, A.R., Polman, R.C.J., Levy, A.R. \& Borkoles, E. (2010). The Mediating Role of Coping: A Cross-Sectional Analysis of The Relationship Between Coping Self-Efficacy and Coping Effectiveness Among Athletes, International Journal of Stress Management, 17(3), 181-192. https://doi.org/10.1037/a0020064

35. O' Callaghan, L. (2015). Pre-Competition Mental Training, Self-Efficacy and Performance in Amateur Equestrian Athletes, Dublin Business School.

36. Pellietair, L.G., Vallerand, R.J. \& Fortier, M.D. (1995). Toward a New Measure of Intrinsic Motivation, Extrinsic Motivation, and Amotivation in Sports: The Sport Motivation Scale (SMS), Journal of Sport \& Exercise Psychology, 17, 35-55. https://doi.org/10.1123/jsep.17.1.35

37. Rottensteiner, C, Tolvanen, A, Laakso, L, \& Konttinen, N. (2015). Youth Athletes' Motivation, Perceived Competence, and Persistence in Organized Team Sports, Journal of Sport Behavior, 38, (4) $432-449$.

38. Ryan, R. M., \& Deci, E. L. (2000). Self-determination theory and the facilitation of intrinsic motivation, social development, and well-being. American psychologist, 55(1), 68. https://doi.org/10.1037/0003066X.55.1.68

39. Schwarzer, R. (Ed.) (1992). Self-efficacy: Thought control of action. Washington, DC: Hem sphere.

40. Sinden, L. M. (1999). Music performance anxiety: Contributions of perfectionism, coping style, selfefficacy, and self-esteem. Dissertation Abstracts International Section A: Humanities and Social Sciences, 60(3-A), 0590. 
41. Schoeman, H, Coetzer, E, Watkin, S, Shaw, B, Lombard, A, \& Shaw, I (2014). Role of Physical Fitness Parameters in Squash Performance, African Journal for Physical, Health Education, Recreation \& Dance, 20 (3), 955-962.

42. Schwarzer, R. (1992). Self-Efficacy: Thought Control of Action. Bristol, PA: Hemisphere Pub. Corp.

43. Smith, R.E., Smoll, F.L. \& Barnett, N.P. (1995). 'Coaching the Coaches', Current Directions in Psychological Science, 6, pp. 16-21. https://doi.org/10.1111/1467-8721.ep11512606

44. Smoll, F. L., Smith, R. E. \& Cumming, S. P. (2007). Effects of A Motivational Climate Intervention For Coaches On Changes In Young Athletes' Achievement Goal Orientations. Journal of Clinical Sport Psychology, 1 (1). 23-46. https://doi.org/10.1123/icsp.1.1.23

45. Træen, B., Westerberg, A.C., Njøten, M.O. \& Røysamb, E. (2015) Predictors of Self-Efficacy in Norwegian Competition Riders, Journal of Equine Veterinary Science, 35(10), 807-814. https://doi.org/10.1016/i.jevs.2015.07.021

46. Vargas-Tonsing, T.M. (2009). An Exploratory Examination of the Effects of Coaches' Pre-Game Speeches on Athletes' Perceptions of Self-Efficacy and Emotion, Journal of Sport Behavior, 32(1).

47. Van Dierendonck, M. \& Goodwin, D. (2005). Social Contact in Horses: Implications For HumanHorse Interactions. 65-81.

48. Van De Mortel, T.F. (2008). Faking It: Social Desirability Response Bias in Self-Report Research. Australian Journal of Advanced Nursing, 25(4), 40.

49. Von Borstel, U. (2007). Fear In Horses And How It Is Affected By The Rider, Training, and Genetics. Faculty of Graduate Studies, University of GuelpWard, Guelph, 136.

50. Weiner, B. (1974). Achievement Motivation and Attribution Theory. Morristown, N.J.: General Learning Press.

51. Beauchamp, M. R., \& Whinton, L. C. (2005). Self-Efficacy and Other-Efficacy in Dyadic Performance: Riding as One in Equestrian Eventing. Journal of Sport and Exercise Psychology, 27(2), 245-252. http://doi.org/10.1123/isep.27.2.245

52. Wilcox, S. (1973). The Event Horse. London: Pelham Books Ltd.

53. Wolframm I.A., \& Micklewright D. (2009). Pre-Competitive Levels of Arousal and Self-Confidence Among Elite and Non-Elite Equestrian Riders, Comparative Exercise Physiology. 5 (3-4) 153-159. https://doi.org/10.1017/S1478061509356133

54. Wolframm, I.A., Shearman, J., \& Micklewright, D. (2010). A Preliminary Investigation into Precompetitive Mood States of Advanced and Novice Equestrian Dressage Riders. Journal of Applied Sport Psychology, 22 (3), 333-342. https://doi.org/10.1080/10413200.2010.485544

55. Yerkes, R.M. \& Dodson, J.D. (1908) 'The Relation of Strength of Stimulus to Rapidity of HabitFormation', Journal of Comparative Neurology and Psychology, 18(5), 459-482. https://doi.org/10.1002/cne.920180503 